\title{
Anopheles gambiae: historical population decline associated with regional distribution of insecticide-treated bed nets in western Nyanza Province, Kenya
}

M Nabie Bayoh ${ }^{1,2}$, Derrick K Mathias ${ }^{1,2,5}$, Maurice R Odiere ${ }^{1,2}$, Francis M Mutuku², Luna Kamau ${ }^{3}$, John E Gimnig ${ }^{4}$, John M Vulule', William A Hawley ${ }^{4}$, Mary J Hamel ${ }^{2,4}$, Edward D Walker ${ }^{5^{*}}$

\begin{abstract}
Background: High coverage of insecticide-treated bed nets in Asembo and low coverage in Seme, two adjacent communities in western Nyanza Province, Kenya; followed by expanded coverage of bed nets in Seme, as the Kenya national malaria programme rolled out; provided a natural experiment for quantification of changes in relative abundance of two primary malaria vectors in this holoendemic region. Both belong to the Anopheles gambiae sensu lato (s.l.) species complex, namely A. gambiae sensu stricto (s.s.) and Anopheles arabiensis. Historically, the former species was proportionately dominant in indoor resting collections of females.

Methods: Data of the relative abundance of adult A. gambiae s.s. and A. arabiensis sampled from inside houses were obtained from the literature from 1970 to 2002 for sites west of Kisumu, Kenya, to the region of Asembo ca. $50 \mathrm{~km}$ from the city. A sampling transect was established from Asembo (where bed net use was high due to presence of a managed bed net distribution programme) eastward to Seme, where no bed net programme was in place. Adults of A. gambiae s.l. were sampled from inside houses along the transect from 2003 to 2009, as were larvae from nearby aquatic habitats, providing data over a nearly 40 year period of the relative abundance of the two species. Relative proportions of A. gambiae s.s. and A. arabiensis were determined for each stage by identifying species by the polymerase chain reaction method. Household bed net ownership was measured with surveys during mosquito collections. Data of blood host choice, parity rate, and infection rate for Plasmodium falciparum in A. gambiae s.s. and A. arabiensis were obtained for a sample from Asembo and Seme from 2005.
\end{abstract}

Results: Anopheles gambiae s.s. adult females from indoor collections predominated from 1970 to 1998 (ca. 85\%). Beginning in 1999, A. gambiae s.s decreased proportionately relative to A. arabiensis, then precipitously declined to rarity coincident with increased bed net ownership as national bed net distribution programmes commenced in 2004 and 2006. By 2009, A. gambiae s.5. comprised proportionately ca. 1\% of indoor collections and A. arabiensis 99\%. In Seme compared to Asembo in 2003, proportionately more larvae were A. gambiae s.s., larval density was higher, and more larval habitats were occupied. As bed net use rose in Seme, the proportion of A. gambiae larvae declined as well. These trends continued to 2009. Parity and malaria infection rates were lower in both species in Asembo (high bed net use) compared to Seme (low bed net use), but host choice did not vary within species in both communities (predominantly cattle for A. arabiensis, humans for A. gambiae s.s.).

\footnotetext{
* Correspondence: walker@msu.edu

${ }^{5}$ Department of Microbiology and Molecular Genetics, Michigan State University, East Lansing, Ml, 48824, USA
} 
Conclusions: A marked decline of the A. gambiae s.s. population occurred as household ownership of bed nets rose in a region of western Kenya over a 10 year period. The increased bed net coverage likely caused a mass effect on the composition of the A. gambiae s.l. species complex, resulting in the observed proportionate increase in A. arabiensis compared to its closely related sibling species, A. gambiae s.s. These observations are important in evaluating the process of regional malaria elimination, which requires sustained vector control as a primary intervention.

\section{Background}

Recent progress in reducing malaria morbidity and mortality in Africa is founded upon expanded coverage of insecticide-treated bed nets (hereafter, bed nets), indoor residual spraying, and combination drug therapy [1]. For this progress to translate into the ambitious goal of malaria elimination, most agree that vector control has a central role [1-3]. Yet, there is an incomplete understanding of how these insecticide-based interventions affect vector populations during long-term implementation, even though a long-term perspective $(10+$ years $)$ is required to comprehend well the relationship between effectiveness of anti-vector measures and prevalence of malaria infection in humans [4].

Vector populations can respond behaviourally, numerically, or evolutionarily to insecticides implemented against them in malaria control programmes. With regard to behaviour, females of some Anopheles species show elevated activity due to the excitation effects of the active ingredients in some insecticide formulations of indoor residual sprays or insecticide-treated bed nets, resulting in their movement away from the sprayed walls or treated nets, with or without having obtained a human blood meal [5-8]. With regard to numeric responses to these interventions, malaria vector populations typically diminish in density and have reduced longevity [9-11]. For example, Anopheles gambiae s.l. and Anopheles funestus population density declined markedly in a randomized evaluation trial of permethrin-treated bed nets in treatment compared to control villages in western Kenya [12], an effect which persisted for three years after the trial ended and after all villagers were given treated nets that were retreated at 6-9 month intervals [13]. Evolutionary responses typically involve changes in phenotypic sensitivity to the insecticides being used, when alleles associated with reduced target site sensitivity or enhanced metabolic detoxification increase in frequency [14].

In the present study, research was focused on the population numeric responses of Anopheles gambiae s.l. mosquitoes to long-term implementation of insecticidetreated bed nets in western Nyanza Province, Kenya. This species complex contains six species whose members are indistinguishable morphologically but which differ in certain behavioural and ecological attributes that are important to their vectorial capacity for malaria and for sampling [15-18]. Anopheles gambiae s.s. and Anopheles arabiensis are the two most common members of this complex and the only two found in western Kenya; A. gambiae s.s. feeds mostly on humans, whereas A. arabiensis feeds mostly on cattle and other animals, less so on humans, making it a less efficient but still capable malaria vector $[17,18]$.

The region where the research reported here was conducted, in the Asembo Bay area of Nyanza province in western Kenya, has been an area of active research on effectiveness of insecticide treated bed nets in reducing malaria transmission, and malaria-related morbidity and mortality in people [13,19-21]. In a randomized trial of the effectiveness of permethrin-treated bed nets on malaria infection and transmission commencing in late 1996, all houses in selected villages in Asembo received bed nets, whereas another set received no nets and served as controls; in 1999, houses in all villages received them, leading to high coverage of bed nets there that has been maintained to 2007 through the provision of free retreatment services and periodic net replacement $[13,20]$. The original trial showed that indoor density of Anopheles vectors of malaria diminished substantially, villagers' health improved, and child mortality declined $[19,21]$. These trends were sustained for four years after the trial ended and as net coverage was sustained $[13,20]$. Populations of A. funestus diminished to negligible levels, when bed nets were used at high coverage in the trial in western Kenya, whilst mosquitoes of the A. gambiae s.l. complex persisted as transmission declined [19]. There was no bed net distribution programme in a nearby and identical community called Seme, bordering Asembo to the east [13]. In samples of adult female mosquitoes taken from inside houses between 1999 and 2002, Lindblade et al [13] observed that the proportion of A. gambiae s.s. was significantly less in Asembo (51.2\%) compared to Seme (77.4\%), suggesting that the greater number of permethrin-treated bed nets in Asembo was disproportionately affecting populations of the former species. Building upon this observation, we postulated that populations of A. gambiae s.s. would decline when bed nets were owned and used at high rates, compared to the local sibling species, $A$. arabiensis. The increasing and 
well-documented patterns of bed net coverage in Asembo and Seme allowed a test of this hypothesis by measuring changes in numbers of adult and larval mosquitoes of both species over several years. Further, historical data were obtained to examine multi-decadal trends in changes in the proportions of these two species as the national malaria campaign in Kenya resulted in increases in bed net ownership regionally.

\section{Methods}

\section{Study area}

This study was conducted in Kisumu and Bondo districts in western Nyanza Province, Kenya, extending west of the city of Kisumu to the community of Asembo (Figure 1A). Studies on effects of indoor residual spraying with fenitrothion on malaria vectors were conducted in this area in the early 1970s [22,23]. A randomized, controlled trial of the effect of permethrin-treated, conventional bed nets on vector populations and malaria transmission was conducted in the same area in the late 1990s [21]. That trial was extended to a managed malaria control programme involving retreatment of nets in organized community campaigns at 6-9 month intervals with permethrin until 2002, then with alphacypermethrin until 2007 (20; M.N. Bayoh, M. Hamel, and J. Gimnig, unpublished). The present research was conducted in part of that original bed net study site (Asembo, Rarieda Division, Bondo District, Nyanza Province) and in an otherwise similar area not included in that trial but bordering the eastern part of it called Seme (Kombewa Division, Kisumu District, Nyanza Province) (Figure 1A) [13,20]. Permethrin-treated, conventional bed nets were distributed to half (late 1996) and then all (early 1999) of the residents of Asembo, providing nearly $100 \%$ household ownership and high rates of nightly use $[20,24,25]$. By contrast, there was no bed net distribution programme in Seme, thus coverage was very low (< $5 \%$ of houses; [13]) until the initiation of distribution of long-lasting, insecticide treated bed nets by the Kenyan Ministry of Health to pregnant women and children $<5$ years beginning in 2004 (at subsidized price) followed by a mass campaign targeting children < 5 years conducted in 2006 (free to mothers of children under five years of age) http://www.nmcp.or.ke.

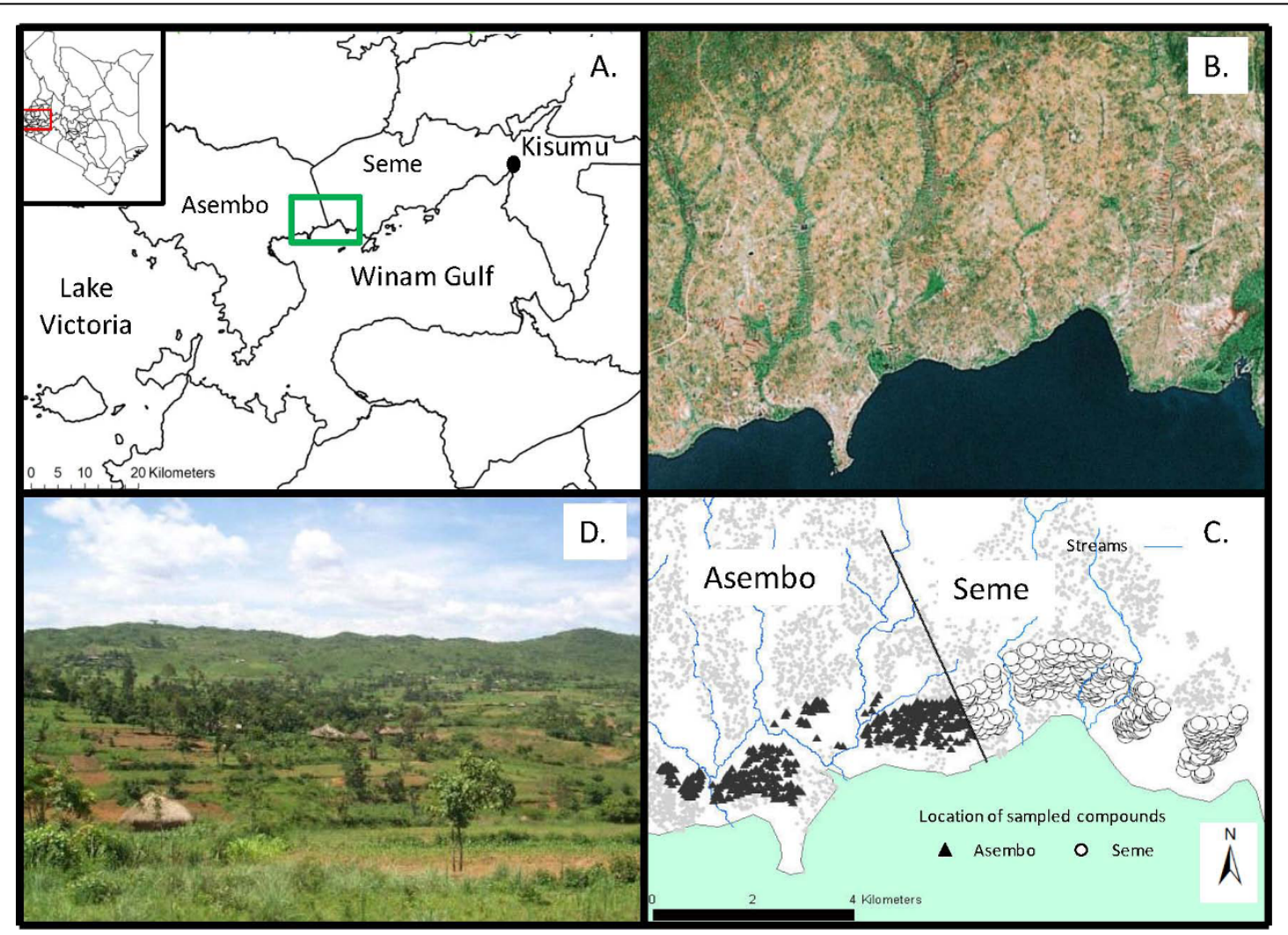

Figure 1 A. Location of study site in western Kenya. Small insert map shows Kenya; red box indicates study region in western Nyanza province. Locations of Asembo and Seme are indicated. Green box indicates sampling transect from 2003 to 2009 (as in B and C). B. Google Earth satellite image of transect region in the Asembo and Seme study area, showing lake plain topography, numerous stream courses, and rural agricultural landscape. C. $12 \mathrm{~km}$ sampling transect from Asembo into Seme, showing location of mapped, sampled compounds in 2003. D. Photograph of study area facing north, showing housing compounds, surrounding farmland, and topography. 


\section{Contemporary sampling}

In 2003, larval mosquitoes were sampled quantitatively using area samplers $[26,27]$ from habitats situated within $200 \mathrm{~m}$ of all housing compounds along a $1 \times 12 \mathrm{~km}$ transect established north of Lake Victoria within Asembo and Seme (Figure 2). Habitats were sampled twice (April-May, and June) in 2003. Adult mosquitoes were sampled inside houses with pyrethrum spray collections [19] in June. From 2006-2009, larval mosquitoes were sampled qualitatively (i.e., without regard to unit area of habitat) using dippers and pipettes along a similar transect during April-June of each year, solely for the purpose of determining the proportions of larvae that were A. gambiae s.s. and A. arabiensis. Adult females were sampled from 20 houses in four discrete sites each along the sampling transect in 2005 [28]. The sampling transect was progressively increased in area from 12, 20, $48,80,80$, and $80 \mathrm{~km}^{2}$ for the years 2003, 2005, 2006, 2007,2008 , and 2009, respectively, with equal areas sampled in Asembo and Seme, and minimally 100 houses sampled. The reason was that $A$. gambiae s.s. had become progressively rarer and mosquitoes overall less abundant, requiring greater sampling area to find individuals of this species. Adult females were sampled in 2005, 2007, 2008, and 2009 from inside houses using either aspiration by hand or the pyrethrum spray catch method for purposes of determining the proportions of the two species as well. Anopheles gambiae s.l. were identified by PCR [29,30], as A. gambiae s.s. or A. arabiensis. Adult mosquitoes sampled from subsets of compounds along the transect in Asembo and Seme in 2005 [28] were dissected to determine parity [31] analysed for host blood using an ELISA procedure with anti-human and anti-bovine

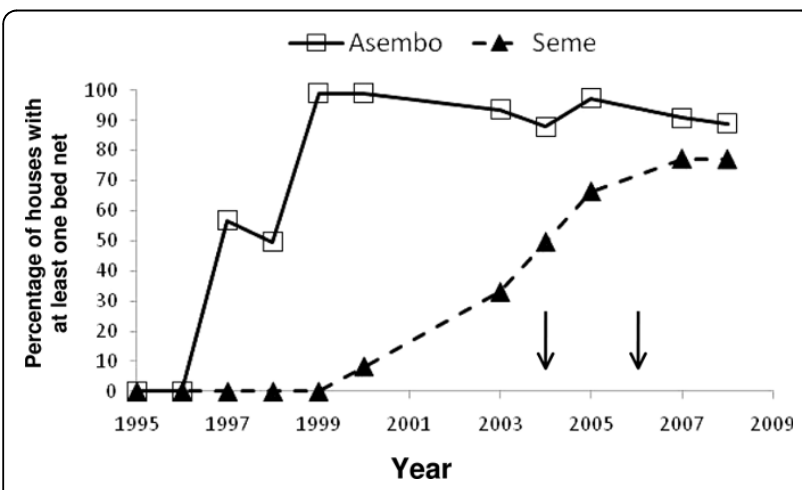

Figure 2 Household ownership of bed nets, defined as at least one per house, of any bed net type and whether treated or untreated, in Asembo (site of bed net trial in the late 1990s) and Seme (no bed net trial) from 1995 through 2008. Arrows indicate the initiation of subsidized national distribution of bed nets through health clinics to pregnant women and children $<5$ years (2004) and a mass campaign during which 3.4 million nets were distributed for free to children $<5$ years in all endemic regions of Kenya (2006). reagents [32], and tested for salivary gland infection for Plasmodium falciparum sporozoites [33].

\section{Bed net ownership}

Bed net ownership in Asembo and Seme was assessed during indoor adult mosquito collections by noting presence or absence of a net, or from cross-sectional surveys conducted by the Kenya Medical Research Institute and US Centers for Disease Control and Prevention. Additional data of bed net ownership from 2003 for Seme were provided by Dr. Mark Polhemus of the Walter Reed Army Institute of Research, Kisumu, Kenya.

\section{Historical data}

Data of the abundance and ratio of adult, female A. gambiae s.s. and A. arabiensis were obtained from indoor collections from nine published studies conducted from 1970 to 2002 in villages in this area (see Additional File 1). Prior to the development of molecular based methods $[29,30]$, the two species were distinguished as "species A" and "species B" by preparation of polytene chromosomes and microscopic examination of banding patterns on chromosome X [18]. Data from these studies were only utilized from locations situated west of the city of Kisumu to Asembo (Figure 2A), so that data of adult females obtained from 2003 to 2009 (see below) would be comparable. Data from other collection sites outside of this lake plain sampling zone were purposefully excluded to remain consistent with the local conditions and mosquito populations under study.

\section{Data analysis}

The effect of sampling location on abundance was assessed by Poisson regression. The proportion of $A$. gambiae s.s. to $A$. arabiensis by distance from the border separating Asembo and Seme was analyzed using logistic regression in the GENMOD procedure, adjusting for clustering and repeated measures. For all transect analyses, tests for trends were done by creating continuous categorical variables based upon distance from the border between Asembo and Seme. Collection sites were grouped into $2 \mathrm{~km}$ categories with the sites furthest inside Asembo assigned a 1 and those furthest inside Seme assigned a 6 . The outputs of the logistic regression analyses, therefore, show the change in the odds that a mosquito would be identified as A. gambiae s.s. for every $2 \mathrm{~km}$, as one moves east from the center of Asembo. For the 2005-2009 samples, data of number of adults and larvae from 2003 provided expected values to test for the effects of increased ITN coverage using $\chi^{2}$ goodness of fit tests. If coverage had no effect on species composition, then the null hypothesis was that 
frequencies in Seme should not differ between 2003 and those years.

\section{Results}

\section{Changes in bed net ownership over time}

In Asembo, the percentage of houses with at least one bed net was $>95 \%$ in 1999 and remained high, although slightly declined, through 2008. Coverage was initially low in Seme, but rose to levels approaching those observed in Asembo by 2008 (Figure 2).

Population dynamics of $A$. gambiae s.s. and $A$. arabiensis In 2003, when bed net coverage was high in Asembo but low in Seme (Figure 2), Seme had a higher proportion of larval habitats with A. gambiae s.l. larvae $(73.8 \%$, $\mathrm{N}=187$ habitats and 1,361 larvae) than Asembo (58.8\%, $\mathrm{N}=102$ habitats and 358 larvae). Further, density of $A$. gambiae s.l. larvae was lower in Asembo than in Seme in each of the two transect sweeps. It was higher overall in the second transect sample compared to the first, likely representing population growth during the course of the rainy season that year (Figure 3A). Density increased significantly with transect sampling position from Asembo to Seme in Poisson regression, and was observed for both sampling events $\left(1^{\text {st }}\right.$ transect sample: risk ratio $=1.28,95 \%$ confidence interval $=1.04-1.58$, $\mathrm{P}=0.006 ; 2^{\text {nd }}$ transect sample: risk ratio $=1.12,95 \%$ confidence interval $=1.02-1.24, \mathrm{P}=0.028$ ). In the first transect sample, the proportion of A. gambiae s.s. larvae relative to $A$. arabiensis was $16.7 \%$ in Asembo but $59 \%$ in Seme (Figure 3B). Similarly, in the second transect sample, the proportion of $A$. gambiae s.s. relative to $A$. arabiensis was $9.0 \%$ in Asembo and $56.6 \%$ in Seme. In both transects, within Asembo, the proportion of $A$. gambiae s.s. increased with decreasing distance to the border with Seme (Figure 3B). The probability that an individual A. gambiae s.l. was identified as A. gambiae s. $s$. increased significantly (logistic regression) with

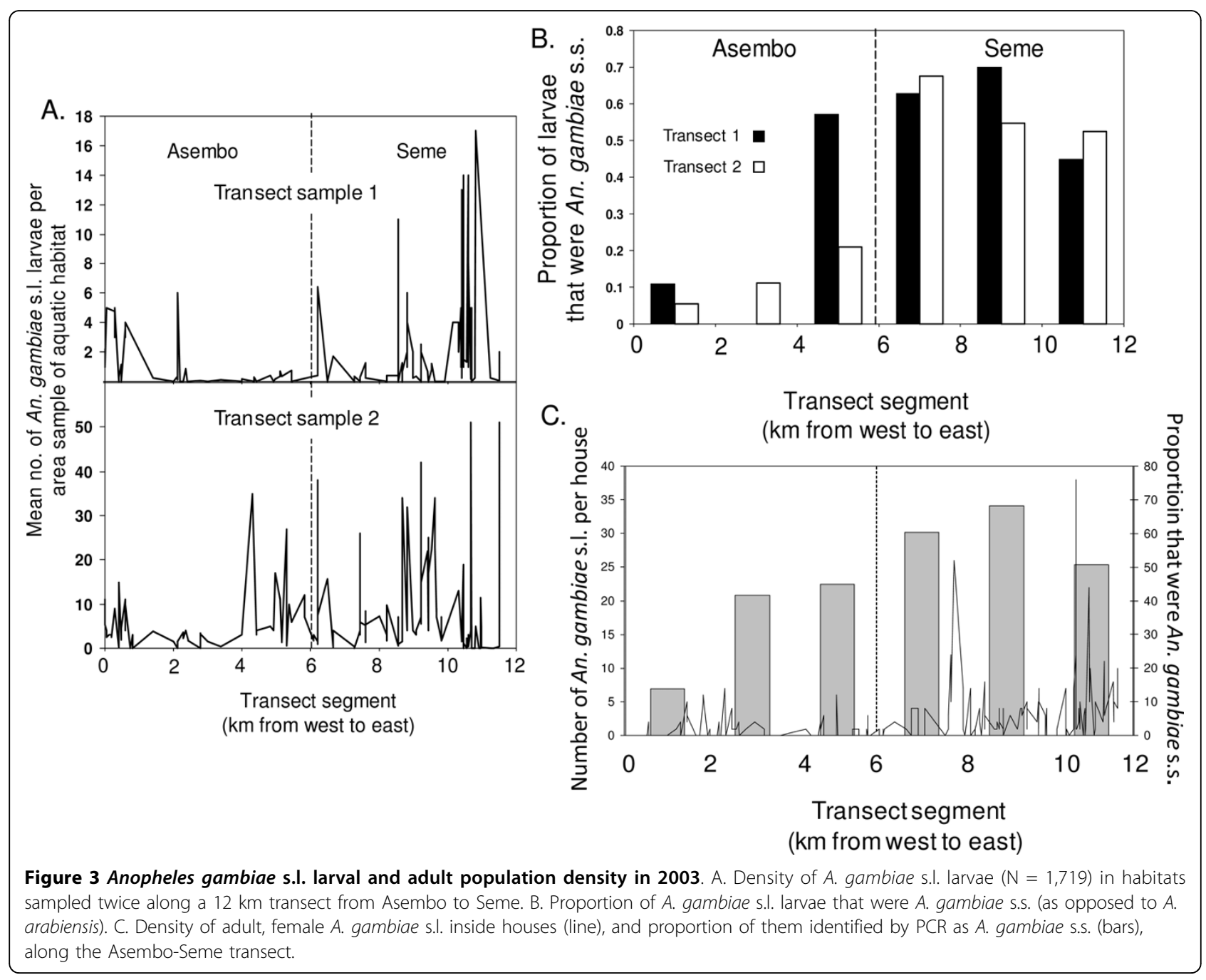


transect sampling position from Asembo to Seme $\left(1^{\text {st }}\right.$ transect: risk ratio $=1.36,95 \%$ confidence interval $=$ $1.09-1.68, \mathrm{P}=0.006 ; 2^{\text {nd }}$ transect: risk ratio $=1.77,95 \%$ confidence interval $=1.49-2.10, \mathrm{P}<0.001$.). Density of adult female $A$. gambiae s.l. inside houses was lower in Asembo than Seme, and the proportion of them that were $A$. gambiae s.s. was lower within Asembo (27.0\%) compared to Seme (58.4\%) (Figure 3C). The probability that an individual, female $A$. gambiae s.l. sampled indoors was A. gambiae s.s. increased significantly from Asembo to Seme along transect sampling points (logistic regression; risk ratio $=1.27, \mathrm{CI}=1.08-1.49, \mathrm{P}=0.009$ ) .

The relative proportions of $A$. gambiae s.s. and A. arabiensis in larval and adult female stages in Asembo and Seme are shown in Figure 4. The proportion of adult females or larvae that was A. gambiae s.s. was lower in Asembo compared to Seme initially and then equalized in later years when $A$. arabiensis dominated both stages. Within Seme, the proportion that was A. gambiae s.s. decreased markedly from 2003 to 2008 (Figure 4). Species composition of females sampled indoors in Seme did not differ significantly between 2003 and $2005\left(\chi^{2}=0.04, \mathrm{df}=1, \mathrm{P}=0.84\right)$. Anopheles gambiae s.s. larvae were significantly less abundant in 2006 compared to $2003\left(\chi^{2}=41.8, \mathrm{df}=1, \mathrm{P}<0.0001\right)$. Anopheles gambiae s.s. larvae and adults were rare in both Asembo and Seme in 2007, when bed net coverage was high in both areas (Figure 4). Of 264 adult specimens identified as A. gambiae s.l. from indoor collections in 2007, only two were $A$. gambiae s.s. (both from Seme). The remainder was $A$. arabiensis. Of 3,185 larvae identified to species in the same year, $26(0.8 \%)$ were A. gambiae s.s., equally from Asembo and Seme. Species composition differed significantly between 2003 and 2007 in Seme, with the proportion of A. gambiae s. $s$. being much lower than expected for adults $\left(\chi^{2}=\right.$ 157.9, $\mathrm{df}=1, \mathrm{P}<0.0001)$ and larvae $\left(\chi^{2}=746.5, \mathrm{df}=1\right.$, $\mathrm{P}<0.0001)$. In 2008, the proportions of larval and adult A. gambiae s.l. that were A. gambiae s.s. remained low in Asembo, but were higher in Seme compared to 2007 (Figure 4). Of 350 adult specimens identified as A. gambiae s.l. from indoor collections, 313 produced PCR amplicons and only $37(11.8 \%)$ were $A$. gambiae s.s. (18 from Seme, 19 from Asembo), the remainder being A. arabiensis. Of 497 larvae identified as A. gambiae s.l., 456 produced PCR amplicons; only 41 (9.0\%) of these were A. gambiae s.s. (eight from Asembo, 33 from Seme). The proportion that was A. gambiae s.s. in 2008 was lower than expected compared to 2003 for adults $\left(\chi^{2}=5.8\right.$, df $\left.1, \mathrm{P}=0.02\right)$ and larvae $\left(\chi^{2}=81.1\right.$, df $1, \mathrm{P}<$ $0.0001)$. In 2009 , only one of $94(1.1 \%)$ adult, female specimens that reacted in PCR was $A$. gambiae s.s.; the others were $A$. arabiensis. The proportion of $A$. gambiae s.s. was significantly lower in 2009 than in $2003\left(\chi^{2}=\right.$ 54.6, df $1, \mathrm{P}<0.0001)$. An additional 128 females that were identified morphologically as A. gambiae s.l. did
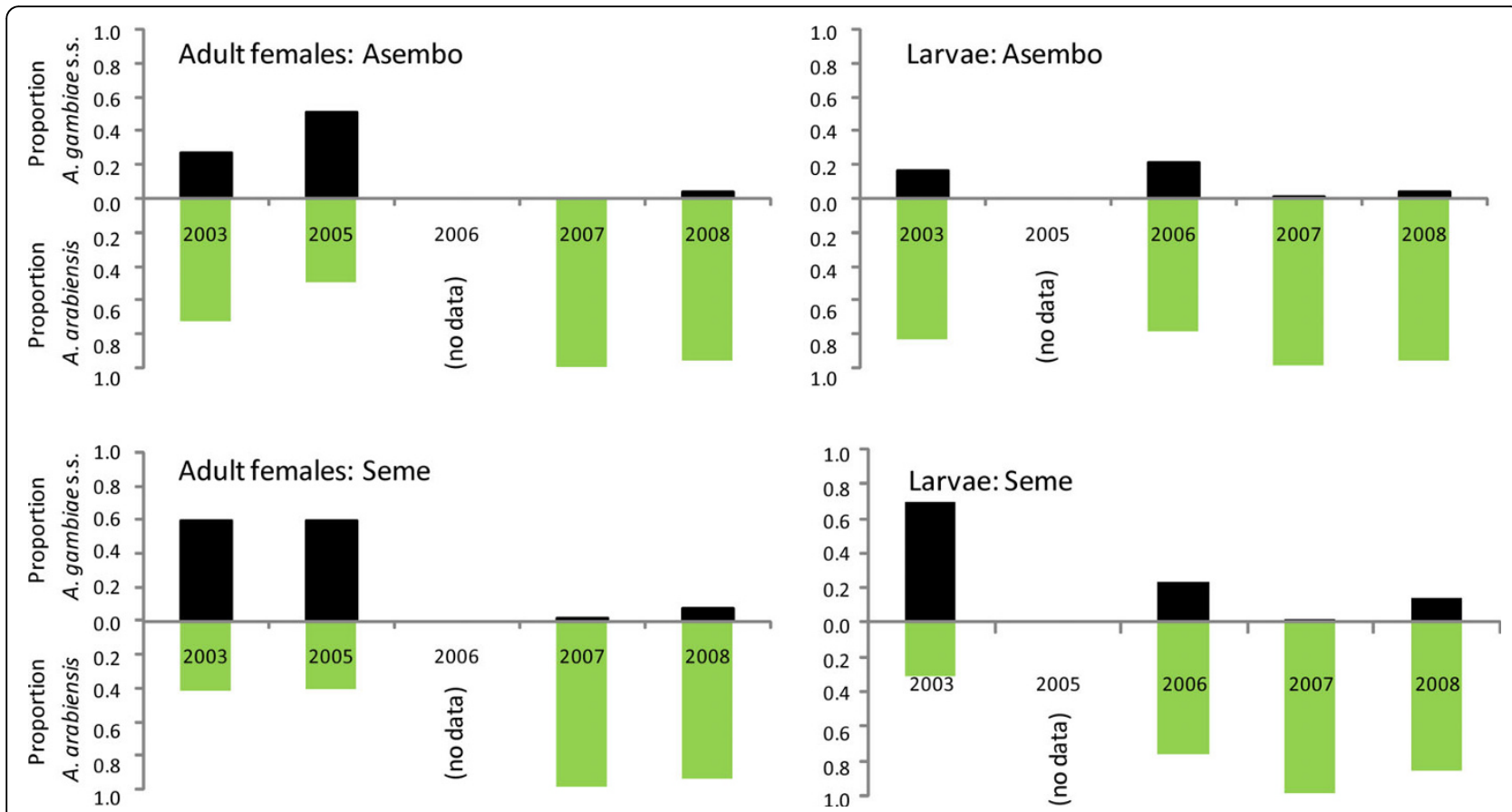

Figure 4 Proportion of $A$. gambiae s.l. adult females and larvae that were identified as A. gambiae s.s. (top, black bars) or $A$. arabiensis (bottom, green bars) from Asembo and Seme in 2003, 2005 (adults only), 2006 (larvae only), 2007, and 2008. 
not react in PCR; due to a storage problem, no A. gambiae s.l. larvae reacted in PCR from 2009 samples, thus, the ratio of $A$. gambiae s.s. and $A$. arabiensis for larvae in that year could not be calculated.

\section{Parity, host choice, and malaria infection}

In 2005, the proportion of females in the parous condition was lower in Asembo compared to Seme for both A. gambiae s.s. in Asembo $(\mathrm{n}=329)$ and A. arabiensis ( $\mathrm{n}=207$ ) (Figure 5A). Based on ELISA for circumsporozoite protein, A. gambiae s.l. had a lower infection rate in Asembo $(0.8 \%, \mathrm{n}=569)$ than Seme $(1.95 \%, \mathrm{n}=$ $1,331)$ although these differences were not significant $(2$ $\times 2$ contingency table, $\chi^{2}=3.23, \mathrm{df}=1, \mathrm{P}=0.07$ ) . A total of 149 A. gambiae s.s. and 153 An arabiensis were tested for blood host (Figure 5B). Anopheles arabiensis fed most frequently on bovines (65\% of blood meals; $22 \%$ mixed bovine/human; $13 \%$ human) and A. gambiae s.s on humans (70\% of blood meals; $21 \%$ mixed human/bovine; $9 \%$ bovine); there were no significant differences in host choice within species between the two sites (A. gambiae s.s.: $\chi^{2}=3.61, \mathrm{df}=2, \mathrm{P}=$ 0.164; A. arabiensis: $\left.\chi^{2}=1.66, \mathrm{df}=2, \mathrm{P}=0.436\right)$;

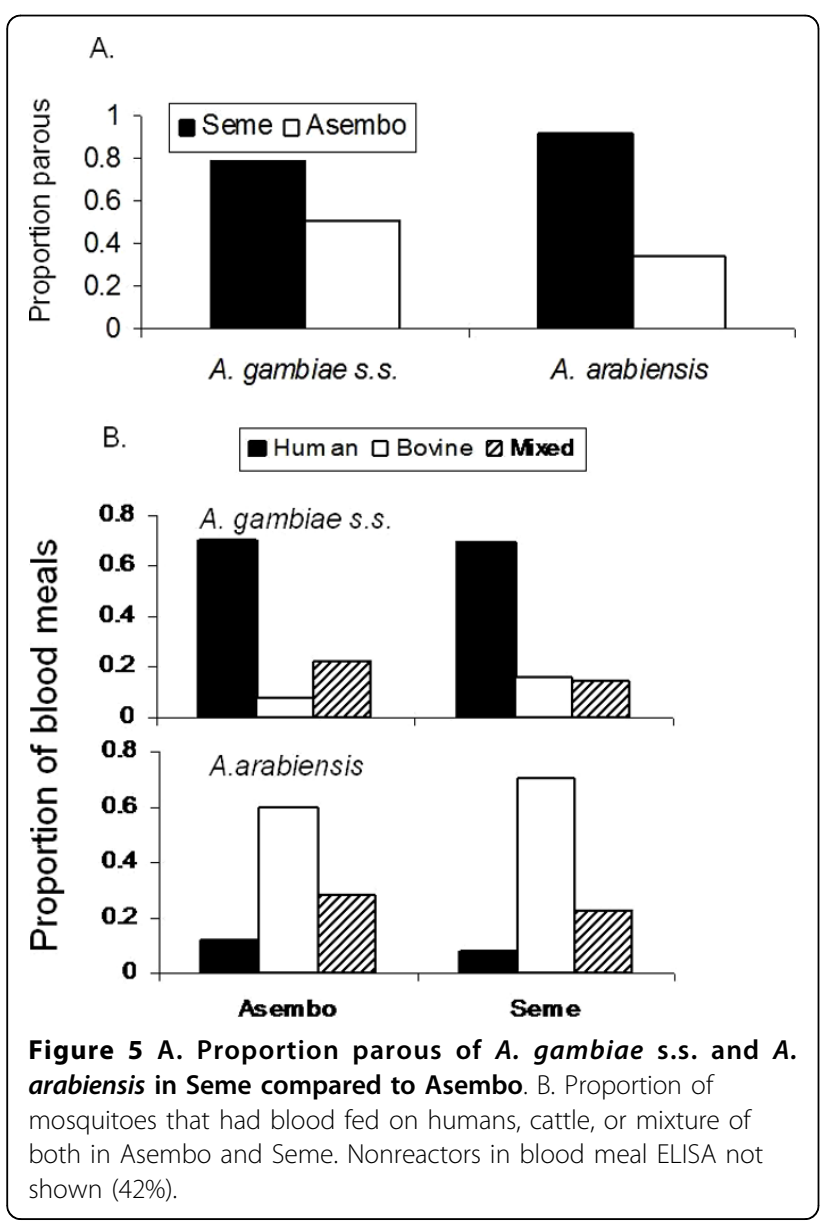

however, host selection was significantly different between mosquito species without regard to study sites $\left(2 \times 3\right.$ contingency table, $\left.\chi^{2}=123.4, \mathrm{df}=2, \mathrm{P}<0.0001\right)$.

\section{Rainfall and temperature}

Data of daily rainfall and average daily temperature from 1990 to 2009 in Kisumu airport showed no aberrant trends (Figure 6).

\section{Historical decline of $A$. gambiae s.s}

The proportion of $A$. gambiae s.s. in samples of females collected indoors, was high relative to $A$. arabiensis from 1970 to 1998, but thereafter declined (Figure 7). By the years 2007-2009, A. gambiae s.s. had become relatively uncommon compared to $A$. arabiensis, such that the ratios of the two species virtually reversed during the course of these few decades. In 2009, A. gambiae s.s. was only $1.1 \%$.

\section{Discussion}

Historical review of data on the relative proportions of A. gambiae s.s. and A. arabiensis females sampled indoors from 1970 to 2002, as well as more contemporary data from sampling efforts of larvae and adult females of these two species reported here, showed a decline in the predominance of the former species with a comparative proportionate increase in the latter species (Figures 3, 4, and 7). Any sampling bias would likely be against $A$. arabiensis females in indoor collections due to their relatively reduced likelihood of entering and resting in houses, compared to A. gambiae s.s. females $[17,18,30]$ thus differential sampling in favor of A. arabiensis is highly unlikely to be an explanation for the trend. As larvae of these species show no habitat segregation in this study area [34,35], changes in larval numbers should accurately reflect population densities and true proportions of the two species, particularly because sampling was done during wet periods, when both species were abundant. The quantitative sampling data from 2003 (Figure 3) and qualitative sampling data to 2008-09 (Figure 4, Figure 7) clearly illustrate a process of gradual extirpation of $A$. gambiae s.s. in the study area, but persistence of $A$. arabiensis. Larval sampling facilitated delineation of this process and should prove useful to others who wish to compare relative changes of the two species under similar conditions.

In Asembo, Seme and regionally, the decline in A. gambiae s.s. coincided geographically and temporally with scale-up of national programmes leading to high rates of household ownership (and presumably, use) of bed nets, suggesting that presence of the bed nets in most houses caused the observed population decline. Alternative explanations seem less likely. First, biased sampling, if having an effect, would have worked against 

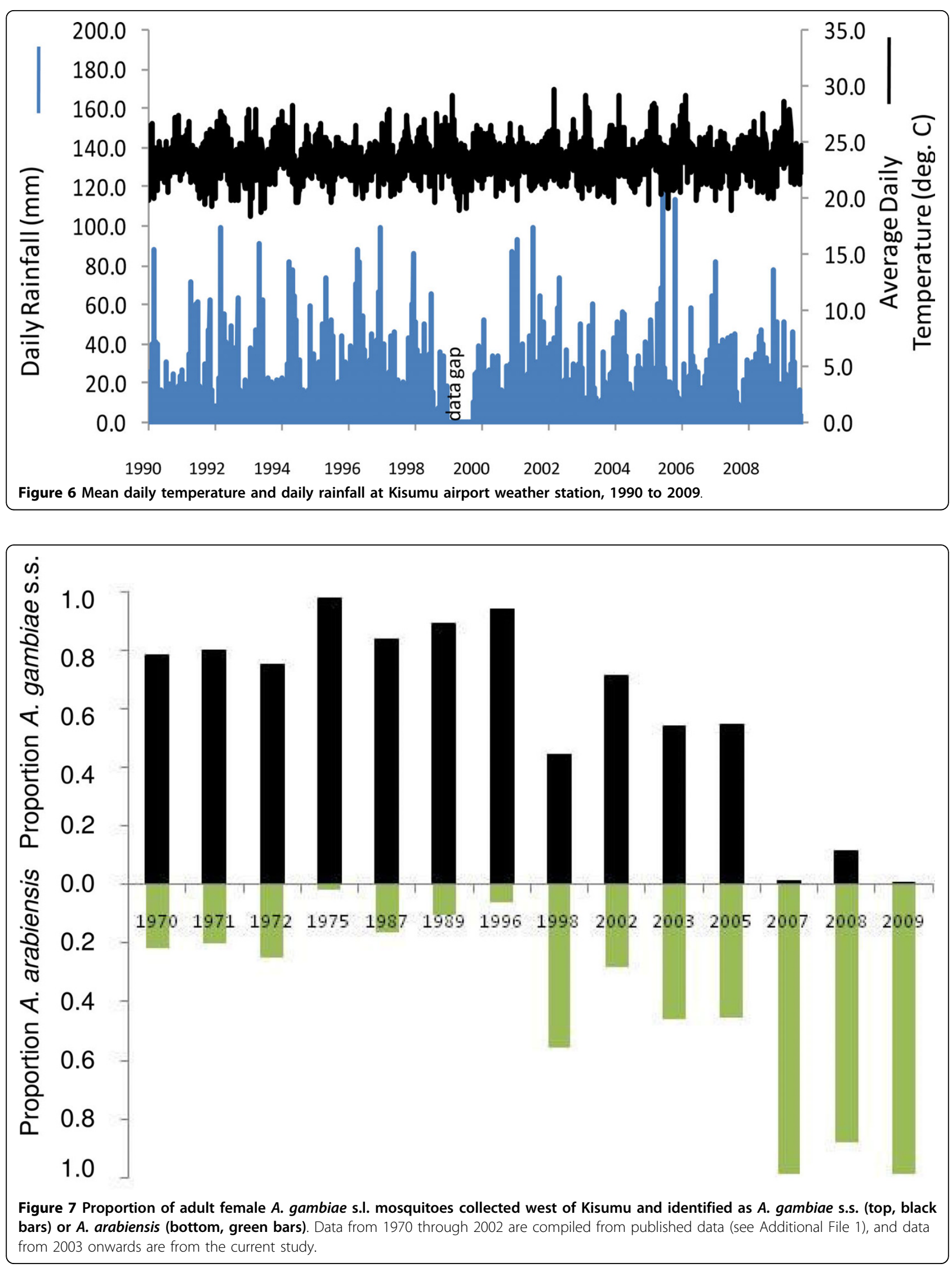
the trend. Second, there was no evidence of an environmental or climate change that could have affected the species distributions locally; indeed, temperature and rainfall were consistently within a normal range across a two decade period (Figure 6). More importantly, a recent prediction from ecological niche models based on climate change scenarios was that $A$. gambiae s.s. should increase while $A$. arabiensis should remain stable or decline regionally [36], opposite of what was observed. Third, the changes might be related to differential abundance of cattle and human hosts. However, in a survey conducted before the current study commenced, both hosts were common in both areas, with about 2.5 cattle and 3.6 people per compound in Asembo and 3.8 cattle and 3.2 people per compound in Seme (J. Gimnig, unpublished data). Cattle are commonly husbanded throughout western Kenya, however, this observation suggests that a greater abundance of $A$. arabiensis in Asembo could not be explained by more cattle there compared to Seme. Fourth, a decline in A. gambiae s.s. populations in Seme subsequent to programmatic scaleup was predicted, based upon the observations from Lindblade et al [13] on proportionate differences of indoor resting, female $A$. gambiae s.s. relative to $A$. arabiensis in Asembo and Seme in 2002, but before the national programme commenced. Results from the present study confirmed this prediction for the prolonged period from 2003-2009, when A. arabiensis adults and larvae profoundly outnumbered A. gambiae s.s. in Asembo and became proportionately dominant in Seme, in sharp contrast to the historic trend prior to arrival of bed nets in that community and in nearby ones. Finally, the correlation through time between increase in bed net ownership (Figure 2) and decrease in A. gambiae s.s. (Figure 4,7 ) could be a mere coincidence, an interpretation which seems highly unlikely given the historical dominance of this species in the region west of Kisumu; and given the results of the intensive transect sampling in 2003 over a relatively short distance $(12 \mathrm{~km})$ (Figure 3$)$.

The most plausible biological mechanism for our primary result is straightforward: bed nets acted as lethal, human-baited traps or as strong repellency devices for the highly anthropophilic, female A. gambiae s.s., causing their population to crash. Aside from direct mortality, blood feeding inhibition, partially due to the exciterepellency effect of bed nets, could induce mortality through deprivation of blood. Fewer and shorter-lived adult A. gambiae s.s. laid fewer eggs in larval habitats, resulting in fewer larvae, reducing larval habitat occupancy and larval density. The decline in A. gambiae s.s. populations is provocative on several levels. First, any malaria control programme is imperfect, with some families not receiving bed nets or, if possessing them, not using them nightly or not retreating them regularly.
In Asembo, recent observations indicate that of those families owning bed nets, only $77 \%$ use them regularly when sleeping (M. Hamel, unpublished data). Thus, ownership does not equate to use. Nets in Asembo were retreated at regular intervals by house to house campaigns through 2003. Thereafter, retreatment was available at central locations at regular intervals and the service was free through 2007, but retreatment rates (not quantified) were certainly never 100\% (M.N. Bayoh, M. Hamel, unpublished observations). In Seme, household ownership of nets increased through efforts by the Kenya Ministry of Health yet remained incomplete after the second roll-out (Figure 2). Nonetheless, a massive population decline in a major, anthropophilic vector occurred despite these imperfections. Second, while $A$. gambiae s.s. historically showed considerable flexibility in resting behaviour when confronted with widespread indoor residual spraying $[8,10,11,14]$, results from the present study suggest less flexibility in host choice (Figure 5B). There was no strong blood host shift to non-humans, nor a shift to predominantly outdoor resting [28], in the face of strong pressure from bed nets. Bogh et al [37] found that A. gambiae s.l. females shifted slightly in host selection away from humans towards cattle when permethrin-treated bed nets were distributed in villages on the Kenya coast. However, the mosquitoes were not identified to sibling species in the complex by PCR, thus any species-specific changes in host selection were not revealed in that study. Third, results reported here are consistent with negligible density-dependent effects influencing A. gambiae s.s. population dynamics. This is in contrast to strong density-dependent controls operating in Aedes mosquito populations [38], but in agreement with results of field studies of $A$. gambiae s.s., which demonstrate only moderate density-dependence [39]. Cumulative adult female mortality due to exposure to pyrethroid toxins in bed nets appears not to be buffered by density-dependent modulation in immature stages, where density-independent processes such as disturbance dominate [26], thus the killing effect of bed nets remains strong even as vector densities are driven low. The increase in bed net coverage described here (Figure 2) likely resulted in reductions in survival, total lifetime fecundity, and basic reproductive number of $A$. gambiae s.s. females in the study area cumulatively over many generations. The relatively lower parity rate observed in A arabiensis compared to A. gambiae s.s. in Asembo compared to Seme in 2005 might be interpreted as a greater effect of bed nets on the former species, potentially confounding the interpretation of the mechanism of decline of the latter species. However, sampling bias against $A$. arabiensis resting and feeding outside of the peridomestic setting would result in over-sampling of those female $A$. 
arabiensis affected by bed nets indoors, therefore explaining the apparent discrepancy $[17,18]$.

The decline of an anthropophilic, anopheline mosquito species; and corresponding proportionate rise of a zoophilic one; during malaria vector control has rarely been reported in Africa. In the Pare-Taveta region of northern Tanzania and southeastern Kenya, indoor residual spraying with dieldrin resulted in the near elimination of A. funestus, whilst absolute numbers of the closely related but zoophilic species, Anopheles rivulorum, increased dramatically [40]. Even though spraying ceased in 1959, A. funestus populations and malaria transmission remained suppressed into 1966 [41], demonstrating long-term and vigorous effects of the original programme. The increase in not just proportion, but density of $A$. rivulorum, was unexpected and difficult to explain. Anopheles funestus has not been replaced by $A$. rivulorum in the Asembo area, A. funestus populations remain very low $[27,30]$, nor $\operatorname{did} A$. arabiensis increase in absolute numbers as $A$. gambiae s.s. declined (see Figure 3). In western Kenya, near the Asembo study site, an indoor residual spray programme using fenitrothion resulted in a moderate increase in the proportion of adult $A$. arabiensis compared to A. gambiae s.s. [42], but species structure of larval populations did not shift in tandem, and both the intervention and evaluation periods were short-term, not allowing for analysis of long-term effects as done here. In the Garki project in northern Nigeria, there was no observed shift in proportions of the two species after a period of indoor residual spraying, although entomological surveillance was a minor component of that evaluation [43]. In South Africa, where indoor residual spraying was implemented effectively to reduce malaria burden, A. gambiae s.s. apparently disappeared whereas the zoophilic species Anopheles quadriannulatus (also a member of the A. gambiae s.l. complex, but not a malaria vector) persisted, and residual malaria transmission was attributed to $A$. arabiensis [4]. However, these changes were qualitatively documented and no larval data were available for unbiased comparisons of changes in relative species abundance. During the malaria eradication campaign in British Guiana from 1945 to 1949, involving application of DDT on the inner walls of houses as a residual insecticide, larvae and adults of the primary vector (Anopheles darlingi) were originally numerous but disappeared, whereas larvae and adults of a zoophilic species, Anopheles aquasalis, persisted [44].

The marked decline in A. gambiae s.s. in western Kenya has been associated with a simultaneous decline in malaria prevalence from 70\% between 1997-1999 [45] to ca. $25 \%$ in 2008 in children < 5 years old (M. Hamel, unpublished data). In eastern Kenya, malaria cases declined in children over the time period of 1997 to
2007, with a steep drop after 2004 [46], when the national bed net distribution programme began in earnest; however, O'Meara et al [46] could not conclude definitively that the decline in malaria cases was due solely to increased bed net use. By contrast, a similar marked decline in malaria cases in The Gambia over the same time period appeared to be related mainly to increased use of bed nets [47]. However, neither the eastern Kenya nor The Gambia study provided mosquito community composition data to correlate with the declines in malaria in humans. The implication of the research reported here is that sustained, high coverage of bed nets should dramatically reduce malaria transmission by A. gambiae s.s., leaving residual transmission by $A$. arabiensis (see Additional File 2). Indeed, the ratio of A. gambiae s.s. to A arabiensis under conditions where both species occur and are transmitting malaria may be a useful relative index of programme effectiveness in places where the former species has been historically the dominant vector, as was the case in parts of southern Africa [4]. With wide coverage of expanded interventions like the one described here, malaria transmission should suffer a precipitous decline mediated through profound effects on vector populations, driving transmission downward and significantly closer to the goal of elimination. Killeen et al [48] proposed the need for higher coverage of bed nets when $A$. arabiensis becomes the dominant vector, if elimination is to be achieved; the opportunity to test this hypothesis is now available. The need for alternative control methods for A. arabiensis is also apparent.

Recent perspectives on the process of elimination propose a shift from population-based coverage of interventions to a clinical surveillance-based system with expanded drug treatment [3]. Results provided here, by contrast, illustrate the crucial importance of long-term maintenance of high coverage interventions against transmission (such as insecticide-treated bed nets) to ensure continual suppression of key vector species, coupled with long-term vector surveillance as a means of continually assessing programme effectiveness, such as by quantifying species ratios, host selection patterns, and parity rates.

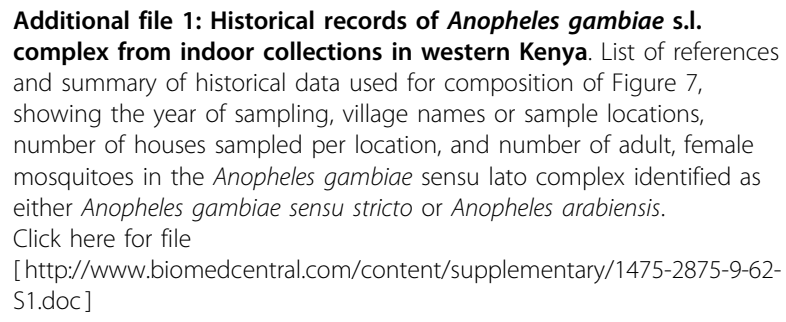


Additional file 2: Estimation of vectorial capacity. For illustrative purposes, vectorial capacity was calculated for A. gambiae s.s. and A. arabiensis before and after scale-up of bed nets, using data from Asembo and Seme.

Click here for file

[http://www.biomedcentral.com/content/supplementary/1475-2875-9-62S2.doc ]

\section{Acknowledgements}

The field and laboratory work of Maurice Ombok, Samson Otieno, Ben Oloo, Thomas Amimo (deceased), Richard Owera, Richard Nyawalo, Joseph Nduati, Mercy Nduta, Lucy Njeri Edwards, and Eric Ochomo is gratefully acknowledged. This study was supported by a cooperative agreement between the Centers for Disease Control and Prevention and the Kenya Medical Research Institute, by NIH grants Al50703 and Al05842, and NSF grant EF-072377. DM was partially supported by a postdoctoral fellowship from the American Society for Microbiology. Reagents for the sporozoite ELISA (MRA-890, deposited by RA Wirtz) were provided by the Malaria Research and Reference Reagent Resource Center. This paper is published with the permission of the director of the Kenya Medical Research Institute (KEMRI).

\section{Author details}

${ }^{1}$ Centre for Global Health Research, Kenya Medical Research Institute, PO Box 1578, Kisumu, Kenya. ${ }^{2}$ Centers for Disease Control and Prevention, PO Box 1578, Kisumu, Kenya. ${ }^{3}$ Centre for Biotechnology Research and Development, Kenya Medical Research Institute, Nairobi, Kenya. ${ }^{4}$ Division of Parasitic Diseases, Centers for Disease Control and Prevention, Atlanta, GA, 4770 Buford Hwy., Mailstop F-42, Atlanta GA 30341, USA. ${ }^{5}$ Department of Microbiology and Molecular Genetics, Michigan State University, East Lansing, MI, 48824, USA.

\section{Authors' contributions}

$M N B, J E G, W A H, J M V$, and EDW designed the study and wrote the manuscript. MNB, DKM, FM, MRO, JEG, and EDW sampled and processed mosquitoes; DKM, LK, MRO, and EDW identified mosquitoes of the $A$. gambiae s.l. complex with PCR. MJH, JEG, DM, WAH, and JMV obtained data of bed net ownership. All authors read and approved the final manuscript.

\section{Competing interests}

The authors declare that they have no competing interests.

Received: 8 December 2009

Accepted: 26 February 2010 Published: 26 February 2010

\section{References}

1. Greenwood BM: Control to elimination: implications for malaria research. Trends Parasitol 2008, 24:449-454

2. Enayati A, Lines J, Maharaj R, Hemingway J: Suppressing the vector. Shrinking the Malaria Map: A Prospectus on Malaria Elimination, Chapter 9 San Francisco: The Global Health Group, Global Health Sciences, University of California, San FranciscoFeachem RGA, Phillips AA, Targett GA 2009, Chapter 9.

3. Mendis KT, Rietveld A, Warsame M, Bosman A, Greenwood B, Wernsdorfer WH: From malaria control to eradication: The WHO perspective. Trop Med Int Health 2009, 4:802-809.

4. Mabaso MLH, Sharp B, Lengeler C: Historical review of malaria control in southern Africa with emphasis on use of indoor residual house-spraying Trop Med Int Health 2004, 9:846-856.

5. Taylor RN, Hill MD, Stewart DC, Slatter R, Gichanga M: A field evaluation of permethrin (OMS-182l) and Nrdc 161 (OMS-1998) for residual control of mosquitoes. Mosq News 1981, 41:423-433.

6. Sharp BL, Le Sueur D, Bekker P: Effect of DDT on survival and blood feeding success of Anopheles arabiensis in northern KwaZulu, Republic of South Africa. J Am Mosa Control Assoc 1990, 6:197-202.

7. Miller JR, Siegert P, Amimo F, Walker E: Designation of chemicals in terms of the locomotor responses they elicit from insects: An update of Dethier et al. (1960). J Econ Entomol 2009, 102:2056-2060.
8. Roberts DR, Chareonviriyaphap T, Harlan HH, Hshieh P: Methods of testing and analyzing excitorepellency responses of malaria vectors to insecticides. J Am Mosa Control Assoc 1997, 13:13-17.

9. MacDonald G: The epidemiology and control of malaria London: Oxford University Press 1957.

10. Fontaine RE: The use of residual insecticides for the control of adult mosquitoes. Integrated mosquito control methodologies London: Academic PressLaird M, Miles J 1983, 1:49-81.

11. Gratz NR: The future of vector biology and control in the World Health Organization. J Am Mosa Control Assoc 1985, 1:273-278.

12. Gimnig JE, Kolczak MS, Hightower AW, Vulule JM, Schoute E, Kamau L, Phillips-Howard PA, ter Kuile FO, Nahlen BL, Hawley WA: Effect of permethrin-treated bed nets on the spatial distribution of malaria vectors in western Kenya. Am J Trop Med Hyg 2003, 68(suppl):115-120.

13. Lindblade KA, Gimnig JE, Kamau L, Hawley WA, Odhiambo F, Olang G, ter Kuile Fo, Vulule JM, Slutsker L: Impact of sustained use of insecticidetreated bednets on malaria vector species distribution and culicine mosquitoes. J Med Entomol 2006, 43:428-432.

14. Hemingway J, Ranson $\mathrm{H}$ : Insecticide resistance in insect vectors of human disease. Ann Rev Entomol 2000, 45:371-391.

15. Gillies MT, deMeillon B: The anophelinae of Africa, south of the Sahara Johannesburg: South African Institute of Medical Research 1968.

16. Gillies MT, Coetzee M: A supplement to the anophelinae of Africa south of the Sahara (Afrotropical region) Johannesburg:The South African Institute for Medical Research 1987.

17. Githeko AK, Adungo NI, Karanja DM, Hawley WA, Vulule JM, Seroney IK, Ofulla AVO, Atieli FK, Ondijo SO, Genga IO: Some observations on the biting behaviour of Anopheles gambiae s.s., Anopheles arabiensis, and Anopheles funestus and their implications for malaria control. Exp Parasitol 1996, 82:306-315.

18. Petrarca V, Beier JC, Onyango F, Koros J, Asiago C, Koech DK, Roberts CR: Species composition of the Anopheles gambiae complex (diptera: Culicidae) at two sites in western Kenya. J Med Entomol 1991, 28:307-313.

19. Gimnig JE, Vulule JM, Lo TQ, Kamau L, Kolczak MS, Phillips-Howard PA, Mathenge EM, ter Kuile FO, Nahlen BL, Hightower AW: Impact of permethrin-treated bednets on entomological indices in an area of intense year-round malaria transmission. Am J Trop Med Hyg 2003, 68(suppl):16-22.

20. Lindblade KA, Eisele TP, Gimnig JE, Alaii JA, Odhiambo F, ter Kuile FO, Hawley WA, Wannemuehler KA, Phillips-Howard PA, Rosen DH: Sustainability of reductions in malaria transmission and infant mortality in western Kenya with use of insecticide-treated bednets: 4 to 6 years of follow-up. JAMA 2004, 291:2571-2580.

21. Phillips-Howard PA, Nahlen BL, Kolczak MS, Hightower AW, ter Kuile FO, Alaii JA, Gimnig JE, Arudo J, Vulule JM, Odhacha A: Efficacy of permethrintreated bednets in the prevention of mortality in young children in an area of high perennial transmission in western Kenya. Am J Trop Med Hyg 2003, 68(suppl):23-29.

22. Joshi GP, Service MW, Pradhan GD: A survey of species A and B of the Anopheles gambiae Giles complex in the Kisumu area of Kenya prior to insecticidal spraying with OMS-43 (fenitrothion). Ann Trop Med Parasitol 1975, 69:91-104.

23. Fontaine RE, Joshi GP, Pradhan GD: Entomological evaluation of fenitrothion (OMS-43) as a residual spray for the control of An. gambiae and An. funestus, Kisumu, Kenya. World Health OrganizationNector Biology and Control Unpublished Technical Report 1975, 75:547.

24. Eisele TP, Lindblade KA, Wannemuehler KA, Gimnig JE, Odhiambo F, Hawley WA, ter Kuile FO, Phillips-Howard PA, Rosen DH, Nahlen BL, Vulule JM, Slutsker L: Effect of sustained insecticide-treated bed net use on all-cause child mortality in an area of intense perennial malaria transmission in western Kenya. Am J Trop Med Hyg 2005, 73:149-156.

25. Alaii JA, Hawley WA, Kolczak MS, ter Kuile FO, Gimnig JE, Vulule JM, Ochacha A, Oloo AJ, Nahlen BL, Phillips-Howard PA: Factors affecting use of permethrin-treated bed nets during a randomized controlled trial in western Kenya. Am J Trop Med Hyg 2003, 68(suppl):137-141.

26. Mutuku FM, Bayoh MN, Gimnig JE, Vulule JM, Kamau L, Walker ED, Kabiru E, Hawley WA: Pupal habitat productivity of Anopheles gambiae complex mosquitoes in a rural village in western Kenya. Am J Trop Med Hyg 2006, 74:54-61.

27. Mutuku FM, Bayoh MN, Hightower AW, Vulule JM, Gimnig JE, Mueke JM, Amimo FA, Walker ED: A supervised land cover classification of a western 
Kenya lowland endemic for human malaria: associations of land cover with larval Anopheles habitats. Int J Health Geogr 2009, 8:19.

28. Odiere M, Bayoh MN, Gimnig J, Vulule J, Irungu L, Walker E: Sampling outdoor, resting Anopheles gambiae and other mosquitoes (Diptera: Culicidae) in western Kenya with clay pots. J Med Entomol 2007, 44:14-22.

29. Scott JA, Brogdon WG, Collins FH: Identification of single specimens of the Anopheles gambiae complex by the polymerase chain reaction. Am J Trop Med Hyg 1993, 49:520-529.

30. Walker E, Thibault A, Thelen A, Bullard B, Huang J, Odiere M, Bayoh M, Wilkins E, Vulule J: Identification of field caught Anopheles gambiae s.s. and Anopheles arabiensis by TaqMan single nucleotide polymorphism genotyping. Malar J 2008, 6:23.

31. Detinova TS: Age-grouping methods in Diptera of medical importance Geneva: World Health Organization 1962.

32. Beier JC, Perkins PV, Wirtz RA, Koros J, Diggs D, Gargan TP, Koech DK: Bloodmeal identification by direct enzyme-linked immunosorbent assay (ELISA), tested on Anopheles (Diptera: Culicidae) in Kenya. J Med Entomol 1988, 25:9-16.

33. Wirtz RA, Zavala F, Charoenvit Y, Campbell GH, Burkot TR, Schneider I, Esser KM, Beaudoin RL, Andre RG: Comparative testing of monoclonal antibodies against Plasmodium falciparum sporozoites for ELISA development. Bull World Health Organ 1987, 65:39-45.

34. Gimnig JE, Ombok M, Kamau L, Hawley WA: Characteristics of larval anopheline (Diptera: Culicidae) habitats in Western Kenya. J Med Entomol 2001, 38:282-288.

35. Minakawa N, Mutero CM, Githure JI, Beier JC, Yan G: Spatial distribution and habitat characterization of anopheline mosquito larvae in western Kenya. Am J Trop Med Hyg 1999, 61:1010-1016.

36. Peterson AT: Shifting suitability for malaria vectors across Africa with warming climates. BMC Infect Dis 2009, 9:59.

37. Bögh C, Pedersen EM, Mukoko DA, Ouma JH: Permethrin-impregnated bednet effects on resting and feeding behaviour of lymphatic filariasis vector mosquitoes in Kenya. Med Vet Entomol 1998, 12:52-59.

38. Legros M, Lloyd AL, Huang Y, Gould F: Density-dependent intraspecific competition in the larval stage of Aedes aegypti (Diptera: Culicidae): Revisiting the current paradigm. J Med Entomol 2009, 46:409-419.

39. Gimnig JE, Ombok M, Otieno S, Kaufman MG, Vulule JM, Walker ED: Density-dependent development of Anopheles gambiae (Diptera: Culicidae) larvae in artificial habitats. J Med Entomol 2002, 39:162-172.

40. Gillies MT, Smith A: The effect of a residual house-spraying campaign in East Africa on species balance in the Anopheles funestus Group. The replacement of $A$. funestus Giles by A. rivulorum Leeson. Bull Entomol Res 1960, 51:243-252.

41. Pringle G: Malaria in the Pare area of Tanzania. III. The course of malaria transmission since suspension of an experimental programme of residual insecticide spraying. Trans $R$ Soc Trop Med Hyg 1967, 61:69-71.

42. Service MW, Joshi GP, Pradhan GD: A survey of Anopheles gambiae (sp. A) and An. arabiensis (sp. B) of the An. gambiae (Giles) complex in the Kisumu area of Kenya following insecticidal spraying with OMS-43 (fenitrothion). Ann Trop Med Parasitol 1978, 72:377-386.

43. Molineux L, Gramiccia G: The Garki project: research on the epidemiology and control of malaria in the Sudan savanna of West Africa World Health Organization, Geneva 1980

44. Giglioli G: Eradication of Anopheles darlingi from the inhabited areas of British Guiana by DDT residual spraying. J Nat Mal Soc 1951, 10:142-161.

45. ter Kuile FO, Terlouw DJ, Phillips-Howard PA, Hawley WA, Friedman JF, Kolczak MS, Kariuki SK, Shi YP, Kwena AM, Vulule JM, Nahlen B: Impact of permethrin-treated bednets on malaria and all cause morbidity in young children in an area of intense perennial malaria transmission in western Kenya: cross-sectional survey. Am J Trop Med Hyg 2003, 68(suppl):100-107.

46. O'Meara WP, Bejon P, Mwangi TW, Okiro EA, Peshu N, Snow RW, Newton CR, Marsh K: Effect of a fall in malaria transmission on morbidity and mortality in Kilifi, Kenya. Lancet 2008, 372:1555-1562.

47. Ceesay SJ, Casals-Pascual C, Erskine J, Anya SE, Duah NO, Fulford AJC, Sesay SSS, Abubakar I, Dunyo S, Sey O, Palmer A, Fofana M, Corrah T, Bojang KA, Whittle HC, Greenwood BM, Conway DJ: Changes in malaria indices between 1999 and 2007 in The Gambia: a retrospective analysis. Lancet 2008, 372:1545-1554.

48. Killeen GF, Smith TA, Ferguson HM, Mshinda H, Abdulla S, Lengeler C, Kachur SP: Preventing childhood malaria in Africa by protecting adults from mosquitoes with insecticide-treated nets. PLoS Medicine 2007, 4: e229.

doi:10.1186/1475-2875-9-62

Cite this article as: Bayoh et al:: Anopheles gambiae: historical population decline associated with regional distribution of insecticidetreated bed nets in western Nyanza Province, Kenya. Malaria Journal 2010 9:62.

\section{Submit your next manuscript to BioMed Central and take full advantage of:}

- Convenient online submission

- Thorough peer review

- No space constraints or color figure charges

- Immediate publication on acceptance

- Inclusion in PubMed, CAS, Scopus and Google Scholar

- Research which is freely available for redistribution
C Biomed Central 